\title{
REDESCOBERTA DA MENTE NA EDUCAÇÃO: A EXPANSÃO DO APRENDER E A CONQUISTA DO CONHECIMENTO COMPLEXO*
}

\author{
GiLSON Lima**
}

\begin{abstract}
Somos complexos e inteligentes porque esquecemos, um computador é uma poderosa máquina cognitiva, mas muito menos complexa entre outras questôes, porque não esquece "nunca", porque apenas computa informaçōes e porque não tem um complexo sistema nervoso para uma aprendizagem, que efetivamente transforme seus processos em mudanças e, portanto, conquiste a aprendizagem em conhecimento. (Gilson Lima)
\end{abstract}

\begin{abstract}
RESUMO: Neste artigo tratamos de alguns apontamentos colhidos durante uma pesquisa vinculada à Sociologia das Ciências, mais especificamente das Ciências da Mente. Primeiro realizaremos uma introdução ao tema da redescoberta da mente. A seguir, destacaremos as diferentes modalidades sistemáticas das práticas educativas e das diversificações de seus estados de mentitude. Então discorreremos uma consideração sobre um os resultados da pesquisa que constatou a importância do marcador somático para a memória de longa duração. Por fim, apresentamos uma rápida conclusão.

Palavras-chave: Ciências da mente e educação. Neurociência e educação. Sociologia da educação. Sociologia das ciências.
\end{abstract}

\footnotetext{
* Um fragmento deste artigo foi apresentado no XIII Congresso da Sociedade Brasileira de Sociologia, em maio-junho de 2007, na cidade de Recife, no Grupo de Trabalho 22: Sociedade da Informação e Sociedade do Conhecimento, sob o título: "Redescoberta da mente na educação: apontamento de uma pesquisa”.

** Doutor em Sociologia e professor e pesquisador do Programa de Pós-Graduação de Reabilitação e Inclusão da Rede Metodista de Educação do Sul - Centro Universitário IPA (Porto Alegre, Rs).E-mail: gilson.lima@metodistadosul.edu.br e gilima@gmail.com
} 
Redescoberta da mente na educação: a expansão do aprender...

\title{
THE REDISCOVERY OF THE MIND IN EDUCATION: THE EXPANSION OF LEARNING AND THE CONQUEST OF COMPLEX KNOWLEDGE
}

\begin{abstract}
This paper focuses on some notes picked during a research linked to the Sociology of the Sciences and more specifically to the Sciences of the Mind. After introducing to the theme of the rediscovery of the mind, it stresses the different systematic modalities of the educational practices and the diversifications of their "minditude" states. It then considers one research result that verified the importance of the somatic marker for long term memory and presents a brief conclusion.
\end{abstract}

Key words: Sciences of the mind and education. Neuroscience and education. Sociology of education. Sociology of sciences.

\section{Por que a mente na educação?}

$\mathcal{E}$

ste artigo é produto de uma pesquisa na área da Sociologia das

Ciências, mais especificamente das ciências da mente, escrito para professores, educadores, cientistas e pesquisadores envolvidos com seus bolsistas ou para todos que, de um modo geral, lidam diretamente com a mente e os estados simbióticos de mentitude ${ }^{1}$ no processo de aprendizagem.

As descobertas realizadas sobre a mente humana, nas últimas três décadas, incluem o mapeamento de ressonância encefálica, que estabeleceu novos substratos para o conhecimento da mente, bem como de suas modificações embrionárias e duradouras nos processos de aprendizagem.

Desde muito, os seres humanos se perguntam sobre os mistérios da mente e das possibilidades de conhecimento do conhecimento. Há uma longa trajetória do pensamento ocidental de Platão, Hegel e Descartes, em que a razão é entendida como "a faculdade essencialmente humana", até céticos que afirmaram sobre a impossibilidade de produzirmos e criarmos conhecimento. Pensadores como John Locke e Emanuel Kant também indagaram sobre a razão e seus limites. A filosofia há muito se pergunta se o conhecimento é produzido a partir das condições $a$ priori existentes no sujeito cognitivo-racional, que vai indagar o objeto, para nomeá-lo, classificá-lo, enfim, para conhecê-lo, adaptando-o às suas 
condições inatas. No empirismo, ao contrário, afirma-se, de diferentes modos, que o objeto produz no sujeito o conhecimento a partir das exigências que ele estabelece no seu meio. Nesse sentido, não há condições a priori para que haja conhecimento, mas, sim, que a razão forma-se pelo conjunto do sujeito com a realidade. A partir da idéia de que pensar era o mesmo que imaginar e que imaginar não é a mesma coisa que realidade, uma das perguntas mais intrigantes que os antigos se faziam é: onde se encontrava a sede ou o lugar responsável pela complexidade do pensar e quais serão as implicaçôes desta sede para a conquista do conhecimento e a produção de idéias e de imaginação?

Para alguns dos antigos pensadores gregos, que são praticamente os inventores das práticas sistemáticas educacionais, o cérebro, tal como hoje o conhecemos, localizava-se no fígado. Não foi por acaso que no conhecido mito de Prometeu este teve seu castigo vinculado a dilaceração de seu fígado por uma águia. ${ }^{2}$

Depois, tivemos Platão, um dos grandes filósofos do Ocidente, que formulou mais uma anatomia espiritual, encontrada nos gregos antigos, que é o que entendemos hoje por mente: o apéx. Porém, alguns anos mais tarde, Aristóteles identificou que a idéia da existência de um cérebro não combinava com a concepção que os gregos possuíam. Séculos mais tarde, é digno de nota na história da mente, o filósofo e pensador René Descartes, principal defensor da compreensão dualista do cérebro e da mente, juntando filosofia especulativa teórica com experimentação, abria cérebros de bezerros na Holanda, tentando acomodar a alma dentro da glândula pineal.

Foi assim durante um longo período da história, em que filósofos e cientistas teceram longos debates sobre a existência ou não de um órgão responsável pela "alma" (o pensamento) e qual seria esse "órgão". Os antigos, depois do fígado, apostavam no coração, um órgão "quente", consistente e pulsátil que fica bem no meio do corpo. Aos poucos, o cérebro e o encéfalo foram se firmando como a sede básica responsável pela imaginação, pelo pensamento e por uma imensa gama de processos, tanto de controle como de mobilização de todo o organismo, apesar de ser "frio", gelatinoso e praticamente imóvel (Zimmer, 2004).

Será que a aprendizagem do conhecimento complexo deve restringir-se ao tratamento cognitivista das informações e dos conteúdos? 
Redescoberta da mente na educação: a expansão do aprender...

Encontramos, nos dicionários, que "cognição" é sinônimo de conhecimento. Será? Entendo por cognição apenas um dos processos mentais da complexidade do aprender e do conhecer. Trata-se, especificamente, do processo e tratamento informacional que envolve basicamente raciocínios complexos. Entre razão e emoção, temos um imenso caldo de possibilidades de entendimento e de reduçóes sobre as possibilidades de conhecimento do conhecimento, mas entre conhecimento e cognição, essas possibilidades se reduzem ainda mais.

Certamente que todo o planejamento de processos de aprendizagens simuladas, realizado por um educador, tem por objetivo sua efetiva execução. A relação entre os planos de ensino e a execução dos mesmos não tem sido muito considerada. Mapeamos e destacamos alguns dos itens mais significativos encontrados no planejamento dos educadores para realizarem suas práticas educacionais de ensino, de instrução, de informação e de conhecimento do conhecimento, a saber:

1. De apresentador de dinâmicas informacionais e de conteúdos, para a memória de longo prazo;

2. De execução procedimental, para a realização das atividades de aprendizagens visando à construção de conhecimento;

3. De avaliador de desempenho, ou seja, de evocação de memória de longo prazo;

4. De motivador.

De todos os quatro itens mapeados, o que recebe menos importância nos planejamentos das práticas formativas dos educadores é o do seu papel de motivador. Pesquisas neurocientíficas descobriram, há mais de duas décadas, que, no nível molecular, sem emoção não existe uma aprendizagem complexa, sobretudo de longo prazo. ${ }^{3}$ Isso implica, sobretudo, mudança qualitativa na importância da motivação, dos estímulos ambientais e da cinética corporal, tanto dos estudantes como dos educadores, para a construção e conquista do conhecimento complexo na aprendizagem (Morin, 1987).

Alguns educadores, já há algum tempo, têm indicado e discutido sobre a significação das emoções na aprendizagem (Restrepo, 1998; De Masi, 1997). Também foi muito importante como um marco histórico para este debate entre os educadores o livro de Humberto Maturana (1999), intitulado Emoçôes e linguagem na educação e na política. 
O processo de conhecimento do conhecimento tem na mente sua mais significativa sede de relações e teias para sua efetivação. É interessante que microprocessos moleculares gerem: atenção, memória, cognição, emoção, transportes químicos envolvendo dinâmicas moleculares e celulares (Brizendine, 2006) ${ }^{4}$ e também mobilizem micromovimentos corpóreos provenientes das descargas bioeletroquímicas nas conexões realizadas nos processos informacionais e comunicacionais. Esses microrritnos corporais são expressões de microprocessos celulares que se manifestam e também podem ser devidamente detectados no macroplano da realidade como microcomportamentos ou mais precisamente como microrhythms communicatives (Condon, 1982, p. 53-76). ${ }^{5}$

Hoje, já sabemos que numa comunicação oral, por exemplo, ocorrem trocas de linguagem, não apenas entre o que se diz e o que se escuta, mas em microlinguagens corporal, química e emocional interpostas em múltiplas camadas simultâneas, num vaivém de incessantes microrritimos. Os estudantes escutam, o professor também. Interrompem, gesticulam. Motivam-se e se desmotivam. Interessamse e se desinteressam. Produzem e reproduzem graus variados de participações, atuações, passividades e apatia, capturados pela sensibilidade que dá uma imensa importância aos detalhes considerados "insignificantes" de uma intensa sincronia interacional (Gladwell, 2002, p. 79-83).

Nossas recentes pesquisas, aplicadas através de diários de campo sobre diferentes práticas de aulas teóricas no ensino superior, revelaram que, além dos microrritmos corporais, não são apenas os microgestos que se padronizam, mas o ritmo da conversa também tende a se harmonizar. Quando surgem interaçóes entre educadores e estudantes provocadas por uma exposição teórica, até mesmo o volume e o tom das conversas se equilibram. O que chamamos geralmente de frequiência da fala - número de sons da fala por segundo - se equaliza. ${ }^{6}$ Trata-se de inúmeros processamentos ativos na aprendizagem, que é também metacognitiva. Isto é muito importante para a consolidação da aprendizagem, para uma expansão do conhecimento, ou seja, é necessária a criação de múltiplas e diferentes relações para que os estudantes experimentem e realizem conexões adicionais. $\mathrm{O}$ cérebro também aprende muito diante de um estado de mentidude, de concentração apropriada, mas aprende também, e muito, com o que ocorre na periferia dessa metaconcentração. 
Redescoberta da mente na educação: a expansão do aprender...

É isso que, ao criticarmos o cognitivismo informacional reinante na aprendizagem escolar, advogamos em prol de uma complexa aprendizagem, visando à expansão do conhecimento metacognitivo. Não queremos anular a importância da cognição informacional, apenas interrelacioná-la de modo complexo a uma aprendizagem de inteligência múltipla. Queremos ir além da cognição de uma metacognição, incluindo a reflexão e a análise relacional de temas interpessoais e aprendizagem emocional envolvida em motivações e estímulos afetivos, bem como na realização de movimentos mais flexíveis do corpo, potencializando mais ainda a inteligência cinética.

Três modalidades de aprendizagem escolar e a diversificação de estados de mentitude

Consideremos três grandes modalidades existentes na aprendizagem e o modo como elas influenciam (disparam ou reprimem) as potencialidades nos diferentes estados de mentitude: modalidades de aulas teóricas, de aulas experimentais e de aulas demonstrativas.

\section{Modalidade de aulas teóricas tradicionais}

Salas de aulas tradicionais que, geralmente, envolvem procedimentos de exposiçōes orais, dialogadas, recursos visuais e audiovisuais, tais como ilustraçôes, para a reflexividade teórica almejada.

O que um professor ministra numa aula teórica costumeira, tradicional, é, sobretudo, uma comunicação que interage numa espécie de super reflexos, envolvendo habilidades fisiológicas fundamentais, das quais mal temos consciência e que algumas pessoas dominam melhor do que outras. Foulcault, nas décadas de 1980 e 1990, chamou a atenção dos educadores para a importância do enclausuramento disciplinar e das práticas educacionais como práticas de poder disciplinar (Foulcault, 1979, 1987).

Parte do que significa ter uma personalidade forte ou persuasiva, portanto, é ser capaz de fazer os outros entrarem no seu próprio ritmo e ditar os termos da interação. Podemos dizer que a eficácia de uma aula teórica pode ser medida pelo nível de confiança em uma 
frequêencia detalhada que se expressa numa meticulosa dança microrrítmica.

Então, se somos professores, mesmo há dezenas de anos, podemos então também começar a nos considerar maestros de microrritmos corporais, pois, quando ministramos uma aula, somos também dançarinos e, sejam quais forem os conteúdos de nossas aulas, estamos também ministrando, de algum modo, uma sofisticada aula de dança.

Nos processos de ensino-aprendizagem, os estados de mentitude são condicionados, potencializados e despotencializados de acordo com mobilizações de recursos humanos e físicos, estímulos ou desestímulos estéticos utilizados para a realização de diferentes práticas de sistematização do ato de aprender.

\section{Figura 1}

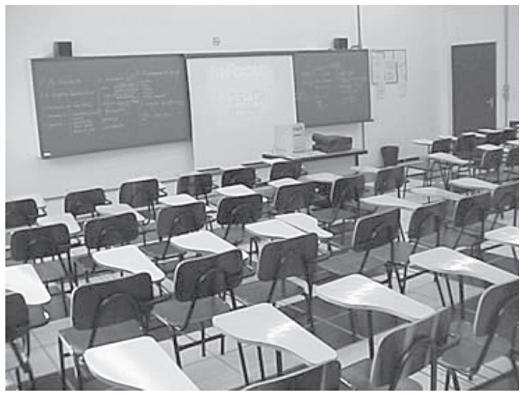

$\mathrm{Na}$ educação formal da sociedade industrial, as salas de aula são montadas como se fossem um casulo, do tipo de uma armadura medieval, visando a limitar e a moldar o corpo e a mente, a fim de tornar-se uma modesta máquina cognitiva, para o mundo do trabalho (Lima, 2007).
Figura 2

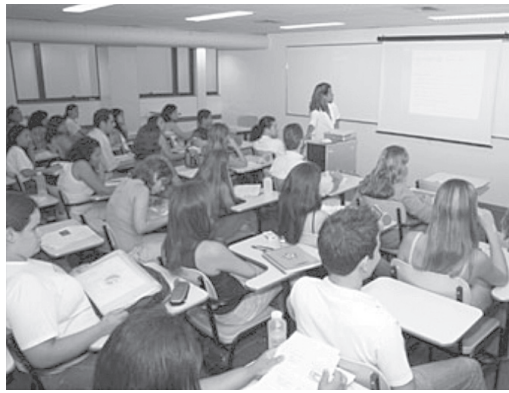

Conexão de sentidos, mobilização do corpo (cinética redutora - concentração). Estados de mentitude que envolvem oralidade, escrita, atenção focal (olho) (Lima, 2007).

\section{Modalidade de aulas experimentais}

Com ambientes e recursos organizados para a possibilidade de realização de experimentos. Geralmente, são laboratórios e oficinas para um aprendizado através de experimentaçōes. 
Redescoberta da mente na educação: a expansão do aprender...

\section{Figura 3}
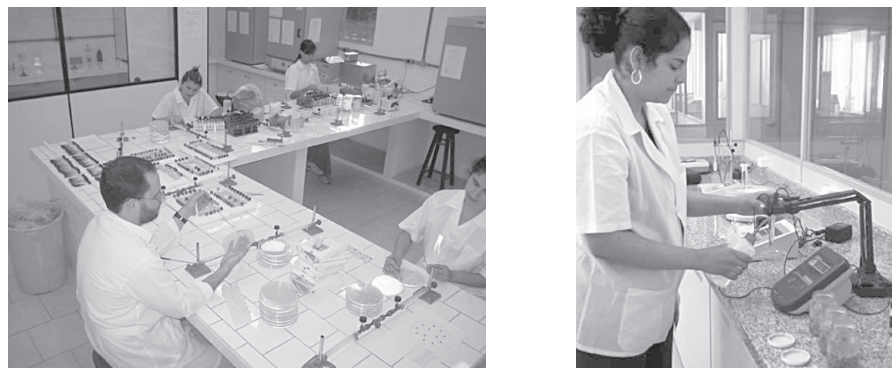

Conexão de sentidos, mobilização do corpo (cinética ampliada ao toque e mais movimentação corpórea) e estados de mentitude que envolvem oralidade, escrita, atenção focal (olho), tato, sentidos diversos (Lima, 2007).

\section{Modalidade de aulas demonstrativas}

Nesta modalidade, a experiência de aprendizagens dos estudantes é direcionada a meios e recursos capazes de demonstrar um ou mais determinados conhecimentos. Podem envolver, também, recursos visuais e audiovisuais como ilustração do conhecimento em demonstração.

\section{Figura 4}
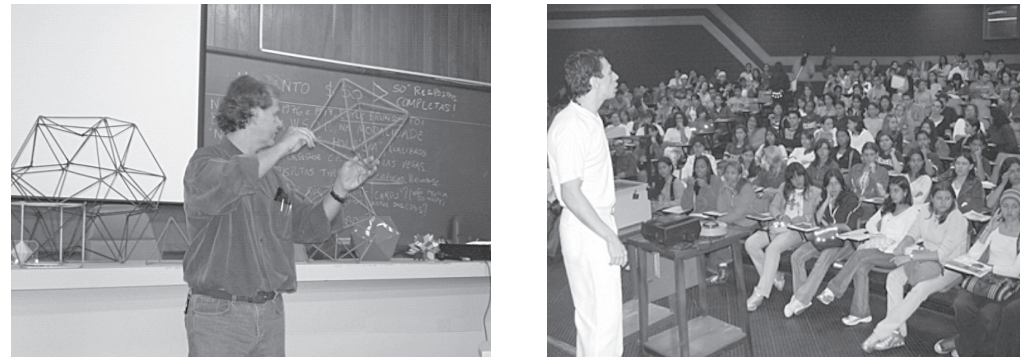

Conexão de sentidos, mobilização do corpo (cinética ampliada concentração, tato, movimentação corpórea). Estados de mentitude que envolvem oralidade, escrita, atenção focal (olho), tato, sentidos diversos (Lima, 2007). 
Nossas pesquisas sobre a criatividade aplicada na aprendizagem, em 2004, já revelaram a importância da experimentação ainda pouco valorizada nos padrões educacionais brasileiros, sobretudo no âmbito do ensino básico. Pesquisas recentes na Itália descobriram que a elevada produtividade criativa dos renascentistas estava vinculada a um tratamento muito singular e significativo da aprendizagem experimental: a bottega.

Bottega era uma espécie de oficina, uma habitação de um ou mais cômodos, na qual um mestre ao mesmo tempo morava e trabalhava, desenhando, esculpindo, pintando, modelando, fundindo suas obras (De Masi \& Frei Betto, 2002). Apenas a cidade de Florença contava, na época do Renascimento, com mais de cinqüenta bottegas. Michelangelo, Donatello, Leonardo e Botticelli, entre outros, foram formados em algumas dessas bottegas, ou seja, oficinas, um tipo de laboratório de experimentações.

Os mestres, em geral, separavam o aprendizado experimental em ambientes de bottega do aprendizado teórico em ambientes conhecido como academias (salas de aulas teóricas). O interessante é que eles migravam de um ambiente para outro com grande flexibilidade, diante de desafios colocados pelas descobertas e pelo aprendizado conquistado.

A grande novidade da metodologia pedagógica inventada na Itália renascentista, que produziu um número significativo de grandes artistas, intelectuais e cientistas, foi operada pela sagaz combinação entre a oficina (laboratórios especializados na modulação da aplicação do conhecimento) e a academia (com lugares especializados na aprendizagem reflexiva do conhecimento complexo).

O trabalho de Marian Diamond (1991) foi pioneiro, ao demonstrar que ratos que estavam em ambientes mais ricos e tinham jaulas mais arejadas, mais atenção, mais chances de brincar livremente ou de pular sobre obstáculos, apresentaram um maior crescimento de células cerebrais. Quando os cérebros desses ratos foram comparados com os dos ratos que estavam em jaulas escuras, isolados e que não tiveram oportunidade de brincar, os resultados apontaram modificações corticais para os ratos de ambiente rico, os quais tinham um número maior de células encefálicas, conhecidas como gliais, apresentando, também, um número maior de conexões celulares. 
Redescoberta da mente na educação: a expansão do aprender...

Durante décadas, fisiologistas se concentravam nos neurônios como os principais comunicadores do cérebro, mas as pesquisas recentes evidenciam cada vez mais que também as células gliais, muito mais numerosas que os neurônios no cérebro, desempenham um papel muito mais importante do que se imaginava (Filds, 2004).

Os ambientes de aprendizagem precisam ser devidamente planejados para possibilitar estímulos estéticos capazes de minimizar as ameaças e estimular a sensibilidade e o aconchego, permitindo organizar novos desafios e conquistas do conhecimento aos alunos. Se possível, em grupos reduzidos, onde se verifica o aumento da participação, a expansão da personalização e da individuação ${ }^{7}$ e da ação coletiva, bem como, e conseqüentemente, do rendimento de todos.

Também como educadores, devemos preparar as instruções informacionais, mas, antes, precisamos nos preparar também para um ambiente favorável à supressão das ameaças que interfiram negativamente no grupo de aprendentes. É necessário que estabeleçamos um clima que favoreça ao máximo os estados de mentitude microcerebrais, que chamamos de alerta relaxado. Por exemplo, não avisarmos que vai haver uma prova. Não temos que fazer uma lista de verdades objetivas, que sejam certas ou erradas. Os resultados das atividades devem estar sempre em aberto e tudo o que delas resultar tem valor. Porém, uma conquista do conhecimento é, antes de tudo, uma conquista de desafios. Assim, remover a ameaça não é o suficiente; temos que lançar os desafios.

Algumas considerações sobre o marcador somático na memória de longa duração

O neurocientista Antônio Damásio demonstrou a importância do estado somático (emocional) para a evocação das memórias, o que ele denominou de hipótese somática da aprendizagem (Damásio, 1996). Hoje, quase nenhum neurocientista nega a hipótese somática para a memória, invertendo a máxima de Descartes, ou seja, para um conhecimento de longo prazo, existir é preciso sentir, tal como: "sinto, logo existo".

No plano macrocomportamental, testamos essa hipótese somática perguntando sobre um evento de alta densidade emocional que é relacionado a uma lembrança para alguém. Realizamos diversas entrevistas 
(2007) e testamos a hipótese somática com uma dezena de professores e estudantes universitários de diferentes gêneros, idades, cursos. Perguntamos se lembravam do momento em que receberam a notícia sobre a queda das torres gêmeas, fato que ocorreu nos Estados Unidos, em 11 de setembro de 2001. Verificamos que 100\% deles lembravam e que a quase totalidade dos entrevistados lembravam, inclusive, o que estavam fazendo logo após o momento em que receberam essa informação.

Perguntamos, também, como é que eles explicavam essa lembrança depois de quase seis anos do acontecido. Em geral, responderam que era porque foi algo muito "significativo", "impactante", "espetacular", "chocante". Como traduzir significativo, impactante e espetacular nesse contexto? É simples: como algo de elevada intensidade emocional. Suas mentes já detectaram, desde o início, que se tratava de uma informação de longo prazo. Trata-se de um acontecimento de tal monta, de elevada carga de intensidade emocional, que o interior de nossa mente é tomado por processos moleculares bioquímicos, que enviam mensagens para todos os recantos do cérebro, formando uma supermemória de longo prazo ou superpotencialização de longa duração (LTP).

Assim como já foi demonstrado a nível molecular em experimentos laboratoriais por neurocientistas (Izquierdo, 2006), também pudemos verificar, no âmbito macrocomportamental da aprendizagem, que, efetivamente, não existe aprendizagem molecular de memória sem envolvimento de emoção, e quanto maior a intensidade da significação emocional, maior será o poder de evocação e da expansão do conhecimento natural e da conquista do conhecimento de longo prazo.

Em âmbito bem geral, os cientistas da mente apresentam diferentes tipos de memória (de curta e de longa duração, operacional, subjetiva, explícita e implícita, episódica e semântica, sensorial, motora, visual-espacial, linguagem e verbal). Para nossos fins, vamos sintetizar em dois os diferentes tipos de memórias: as declarativas e as nãodeclarativas. As memórias não-declarativas incluem uma grande família de diferentes capacidades de lembranças e evocações, que compartilham uma característica particular. São um tipo de memória que envolve diferentes habilidades motoras e sensórias, hábitos e aprendizados emocionais, assim como toda a forma de aprendizado reflexo 
Redescoberta da mente na educação: a expansão do aprender...

(não-reflexivo), tais como a habituação, sensibilização e condicionamento clássico e operante. As memórias não-declarativas envolvem um tipo de conhecimento reflexivo, mas que não exige reflexão, sobretudo, no processo de sua evocação.

Vejamos! Um dia, quando você ou algum conhecido seu iniciou o aprendizado de andar de bicicleta, você teve que envolver uma grande intensidade emocional, muita atenção e uma elevada dose de consciência no processamento de cada um dos microrritmos dessa aventura cinética. No entanto, à medida que andar de bicicleta tornou-se uma prática habituada, as tarefas para isso foram armazenadas na sua mente ou na de seu conhecido como memória não-declarativa.

As memórias declarativas são diferentes das não-declarativas, principalmente por envolver alguma imaginação simbólica reconstrutiva a ser declarada na evocação de sua lembrança (eventos, nomes, conceitos...). Tentemos recordar um nome de um amigo, de uma escola, de um conhecido. Trazer à tona o rosto dessa pessoa, sua voz, sua maneira de falar e suas lembranças conectadas a eventos significativos, tudo isso envolve, de algum modo, na sua evocação, alguma imaginação e uma efetiva reconstrução de cenas ou eventos que ocorreram. Quanto mais longínquo for o tempo em que ocorreu a lembrança, certamente, maior será o grau de significância e intensidade emocional que depositamos nela.

Pensamos agora em três os tipos de memórias declarativas: as memórias de trabalho, que utilizamos para entender a realidade que nos rodeia e que são também importantes para formar as outras memórias declarativas; as memórias de curta duração ou de curto prazo, que duram segundos, minutos, no máximo horas; e as memórias de longa duração ou longo prazo, também chamadas de memória remota e que duram dias, anos ou décadas.

Nas escolas e, sobretudo, nas universidades, lidamos de modo significativo com as memórias declarativas e, mais efetivamente, as de longo prazo para a expansão do conhecimento. No entanto, fazemos isso, infelizmente, sem muita clareza da importância, por exemplo, do conteúdo emocional para o processo de conquista da memória de longo prazo para a efetiva expansão do conhecimento natural.

No entanto, parece que os sistemas escolares de aprendizagem ainda não se deram conta da importância de tratarmos as emoções na 
experimentação do próprio aprender (Maturana, 1999). Ao entrar nas salas de aula, nossos sistemas de ensino induzem os estudantes a fecharem também os portais somáticos, não apenas as portas do mundo vivido, mas, também, ao exercício da aprendizagem de suas próprias emoções para a expansão do conhecimento. As emoções estão então abrigadas, separadas e até mesmo colonizadas pela razão. Como educadores, não fomos sequer preparados em nossa formação para realizarmos uma educação das emoções nas escolas. Tivemos que nos virar para lidarmos com nossas emoçôes sempre que podíamos, mas estávamos solitários nessa missão, éramos, e ainda somos, artesãos entregues ao autodidatismo emocional.

Quais são as implicações da negação do processo somático para práticas escolares que visam à expansão do conhecimento?

As ciências da mente já demonstraram que o aprendizado emocional é um pressuposto-chave para a obtenção de uma efetiva memória de longo prazo. O grave disso é que, para a mente envolvida num evento situacional de aprendizagem, uma memória de longo prazo já deve nascer moldada para efetivamente ser considerada uma memória de longo prazo, e uma memória de curto prazo já nasce também moldada a se tornar uma mera "decoreba" morta, sem vida frente a uma almejada expansão do saber e de conquista do conhecimento, num determinado evento de aprendizagem.

É vital, para a expansão do conhecimento natural, a interligação entre a complexidade emocional e a racional. Educar para a emoção é importante, pois também a própria emoção pode não ajudar e, muitas vezes, não ajuda na conquista do conhecimento complexo.

O problema da não aprendizagem das emoções ligadas ao aprendizado da expansão do conhecimento vem de uma limitação histórica. Certamente que a conquista histórica da razão pelos humanos é de uma façanha tal, que chegamos a pensar que ela é praticamente inata frente aos outros seres. Muitos chegam a pensar que a razão não é uma invenção histórica de nossa evolução, mas algo tido como inato, ou seja, os seres humanos são racionais por filogenia. Por isso, criamos uma civilização, uma civilidade baseada na razão.

Nesse sentido, as emoções não são entendidas como significativas para o processo de aprendizagem complexo. As emoçóes pertencem ao universo da não-racionalidade, da barbárie não-racional, a 
Redescoberta da mente na educação: a expansão do aprender...

qual temos que enfrentar e, sobretudo, vencer, para nos civilizarmos; algo assim como uma expressão evidentemente humana, mas um tipo de expressão primitiva, quando não meramente negativa.

Emoção e razão são fundamentais para a expansão do conhecimento. Encontramos, em dicionários, conceitos de emoção como sendo um abalo afetivo e, de razão, como raciocínio, julgamento. Lidamos com conceitos reducionistas a todo momento, mas sabemos que razão e emoção não são bem isso, mas não sabemos defini-las com precisão.

As emoções envolvem sempre três aspectos: (1) sentimento, que pode ser positivo ou negativo; (2) comportamentos motores, característicos de cada emoção; e (3) ajustes fisiológicos correspondentes. As regiōes neurais envolvidas são, geralmente, reunidas em um conjunto denominado sistema límbico, que agrupa regiōes corticais e subcorticais situadas, principalmente, mas não exclusivamente, nos setores mais mediais do encéfalo. Tomemos, como exemplo, o medo. Inegavelmente, uma expressão emocional vinculada às nossas entranhas, mas que é fundamental para a sobrevivência de nossa espécie.

O medo é uma experiência subjetiva, que surge quando algo nos ameaça e provoca em nós comportamentos de fuga ou luta, ativando o sistema nervoso autônomo, de modo a garantir o dispêndio súbito de energia que se segue para a sobrevivência ameaçada. São mecanismos entranhados, quando somos ameaçados ou sobrepujados, visando garantir a nossa sobrevivência ou da espécie.

As emoções positivas, porém, são pouco conhecidas até mesmo pelos cientistas da mente e podemos defini-las, mas ainda não é possível atribuir-lhes uma base neural segura. Uma abordagem reducionista da emoção acabou por entender os aspectos apenas negativos da emoção, não permitindo verificarmos, nas atitudes e práticas, o envolvimento positivo da emoção para a expansão do conhecimento e a predominância marcante das emoções entre um estado de mentitude sobre o outro nos processos de aprendizagem.

A razão e a emoção são aspectos genéricos de um mesmo contínuo e expressam as mais sofisticadas propriedades do cérebro humano. Como parte dessa continuação, podemos destacar, no extremo racional, operações como o pensamento lógico, o cálculo mental e a resolução de problemas; na ponta emocional, o medo, a agressividade e o 
prazer. No meio, uma infinidade de possibilidades: o comportamento socialmente determinado (ajuste social), a apreciação e a criação artística, a tomada de decisões, o planejamento de açôes futuras. Um contínuo infinito é o que chamamos de estados simbióticos de mentitude.

\section{Palavras finais}

É importante considerarmos, no entanto, que a imersão para uma efetiva aprendizagem, com vistas à expansão do saber e à conquista do conhecimento, encontra-se significativamente envolvida em condições consolidadas de um poder saber disciplinar do corpo e da mente cognitiva para o mundo industrial do trabalho.

$\mathrm{O}$ processo de redescobrimos a mente na educação não se trata apenas de uma mudança no paradigma da macroconcepção pedagógica da educação industrial. Precisamos de novas práticas, novos estímulos estéticos e ambientais, novas dinâmicas de modelaçôes criativas do aprendizado, visando não a mera disciplinarização do corpo e da cognição, mas a efetiva expansão ampliada do saber cada vez mais envolvido numa sociedade que acelera o acesso e a produção da informação e do conhecimento. Dinâmicas de um aprender a saber que valorize a própria experiência desse mesmo saber, um poder aprender. Estamos chamando esse processo, provisoriamente, de pedagogia do acontecimento.

Certamente que isso implicaria vivermos um evento de aprendizagem, não meramente como um fato, uma data, um conteúdo ou um programa apenas planejado, mas como um acontecimento. Os fatos comuns são ordenados no tempo, dispostos em sequiência como uma fila. Ali, eles têm seus antecedentes e suas conseqüências, que se agrupam, pisam nos calcanhares uns dos outros, sem parar, e sem qualquer lacuna (Schultz, 1994).

A vida sempre nos chamou para que tomemos por inteiro os acontecimentos. Para mergulharmos profundamente nos acontecimentos, precisamos que desassosseguemos do sossego funcional dos fatos. Porém, para tomarmos por inteiro os acontecimentos do mundo, precisamos também viver, acontecer também no mundo. Os acontecimentos envolvem, antes de qualquer coisa, mudanças na maneira de pensarmos o mundo. Caso queiramos nos reunir para planejar um novo acontecimento no mundo, antes de ele mesmo acontecer, não podemos esquecer que deveríamos, primeiro, desassossegarmo-nos de nós mesmos. 
Redescoberta da mente na educação: a expansão do aprender...

A expressão "desassossego de si mesmo no mundo" foi pensada por Fernando Pessoa e nos parece interessante aqui, pois "desassossegar de si no mundo" implica uma perturbação (Pessoa, 2001). Mas não uma perturbação qualquer e sim uma perturbação existencial, que inquieta profundamente nossas certezas. Trata-se de um desassossego profundo, íntimo, num milímetro, que termina quando sinto que não esqueço o que sinto e que, pouco a pouco, vai impondo-se e me torna cada vez mais apto ao novo e à inesperada emoção do acontecer (Lima, 2005).

Concordamos com os neurocientistas, quando eles afirmam que processos individuais e coletivos de aprendizagem envolvem também as relaçóes e as associações entre uma ou mais moléculas e que os mecanismos cerebrais da memória e da aprendizagem estão também associados a microprocessos neurais responsáveis pela atenção, percepção, motivação, pensamento e outros processos neuropsicológicos, de forma que perturbações em qualquer um deles tendem a afetar, indiretamente, a aprendizagem e a memória.

Porém, a simbiose da aprendizagem é muito complexa e vai desde o nível quântico molecular ao macrofísico corpóreo e comportamental, em nível individual e coletivo.

Em educação, é preciso que os estudantes tenham experiências ricas, estímulos estéticos e ambientais e, para isso, temos que lhes dar tempo e oportunidades para compreenderem suas experiências e para conquistarem os desafios e o conhecimento complexo. Eles precisam ter oportunidade para refletir, para ver como as coisas se relacionam. Uma das mais ricas fontes de aprendizagem provém de uma pedagogia que acontece na experiência, uma pedagogia evolvida intensamente no acontecimento do aprender a aprender, para efetivamente expandir o saber, o conhecimento.

Assim, reduzirmos o processo de aprendizagem e do conhecimento ao acesso, à produção e à evocação da informação e do tratamento da informação meramente cognitiva é, no mínimo, muito simplificador. Desde o final do século XIX e de modo mais intenso com o surgimento da informática e das ciências cognitivas no século Xx, a cognição foi geralmente compreendida como o espírito ou a própria materialização da inteligência ou do conhecimento (Andler, 1992; Ganascia, 1996). Ou seja, reduzimos a expansão do saber e a conquista 
do conhecimento ao processo mental que envolve o sistema de tratamento da informação.

Praticamente, a cognição virou um objeto de síntese de muitas áreas do saber científico, que organiza numa estruturação híbrida de saberes, que se convencionou chamar de ciências cognitivas, ou, como pretendem alguns, de uma espécie de ciências das ciências ou uma "big ciência" (Pombo, 2004, 2006).

Um dos problemas das ciências cognitivas, diferenciadamente da maioria das abordagens dos neurocientistas, é que a mente não é apenas computacional.

A informática deu as bases para a consolidação das ciências cognitivas, que tem sua importância, mas também seus limites na compreensão sobre os processos de mentitude. $\mathrm{Na}$ verdade, consideramos até mesmo a informática como um campo específico e significativo do que se convencionou a ser chamado, no plural, de ciências cognitivas. Os cognitivistas, em geral, não gostam da explicitação desse vínculo, que demonstra claramente os seus modelos reducionistas da mente humana. A própria neurociência, que, em geral, desconstituiu a abordagem reducionaista da mente computacional, acabou também por dar uma ênfase muito maior a suas pesquisas sobre a dimensão computacional da mente. Basta verificarmos, por exemplo, a importância que foi dada até agora às pesquisas neurofísicas das células neuroniais - que são cerca de 100 bilhōes -, em comparação com a pouca importância que foi dada as células gliais, que existem em quantidade dez vezes maior do que os neurônios no mesmo cérebro humano (Lent, 2004; Filds, 2004). ${ }^{8}$

Isso tem implicaçóes ainda mais profundas nas práticas educacionais e na compreensão sobre a complexidade da conquista do conhecimento do conhecimento. Por exemplo: a redução do conceito de linguagem ao da linguagem computacional; a redução da linguagem filogenética dos processos mentais ao da linguagem léxica e aos símbolos lógicos; a redução do conceito de memória ao da abordagem computacional binária ou de algoritmização; a redução da comunicação à informação cognitiva, esquecendo da comunicação química e emocional.

Assim, alguns educadores acabam por repetir a mesma redução dos conceitos de inteligência e de aprendizagem realizada pelos 
Redescoberta da mente na educação: a expansão do aprender...

cognitivistas da informação computacional e da inteligência artificial (Lima, 2005). Por exemplo, assim como para a informática bastaria aprendermos a programação binária para decifrarmos a linguagem da vida e da mente, para alguns educadores, ensinar a distância nossos jovens, através de sofisticados suportes de máquinas cognitivas informacionais, seria suficiente para a bioexpansão do saber e para a conquista do conhecimento complexo. Assim, ao manipularmos de modo eficaz imagens e símbolos em uma tela de computador, quase que estaremos aptos a sermos efetivamente educados, adquirindo o conhecimento necessário para a vida em sociedade.

Também encontramos nas ciências da mente, sobretudo, na neurologia do comportamento, abordagens de aprendizagens comportamentais muito limitadas e reduzidas à escala micro e neuromolecular, onde a identificação dos processos de ação e reação neurobioquímicas da aprendizagem, entre outras questôes, deixa de fora significativos macro e microprocessos envolvidos na dinâmica vital da aprendizagem, como, por exemplo, a dobra sociológica de todo o comportamento biológico. Uma abordagem que temos chamado de simbiogênica, em homenagem ao microbiologista Lynn Margulis (Lima, 2005).

A idéia de uma dobra dos planos de realidade em micro e macro implica pensarmos a aprendizagem de modo complexo, ao invés de verificarmos corpos, objetos, dados, células e trocas se desdobrando. Deleuze também opera com o universo conceitual de Leibniz e joga com a palavra latina plica (dobra). Dobrar-desdobrar não significa simplesmente tender-distender, contrair-dilatar, mas envolver-desenvolver, involuir-evoluir (Deleuze, 1991).

Isso pressupõe que os estados de mentitude operam nas singularidades microcerebral, macroindividual, comportamental e na dimensão macrossocial, numa complexa simultaneidade da complexidade. Por isso, precisamos de uma pesquisa que se opere de modo multidisciplinar no diálogo da educação com as ciências da mente, no plural.

Os neurocientistas se limitam muito à dimensão do comportamento individual e social, de âmbito micromolecular. Os educadores, sociólogos e filósofos da mente, com algumas exceçôes, se concentram mais no plano do macrocomportamental.

Hoje, já sabemos que a mente é um grande organismo de secreção. Processa muito e secreta tudo o que processa. É por isso que 
estudiosos da memória, como o pesquisador Ivan Izquierdo, afirmam que a complexidade da memória humana reside no esquecimento e não na lembrança, ou melhor, na sabedoria e na arte do esquecimento (Izquierdo, 2004).

Aqui, começamos uma primeira e importante lição com a descoberta da mente na educação: aprender a esquecer é, assim, muito mais importante do que aprender a lembrar. Um dos mais significativos processos para a aprendizagem complexa é a sabedoria frente ao esquecimento e não o "informatês" conteudista e memorialista tão proliferado em nossas práticas educacionais, nas modernas sociedades industriais.

Somos complexos porque esquecemos. Um computador é uma poderosa máquina cognitiva, mas muito menos complexa entre outras questôes, porque não esquece "nunca", porque apenas computa informaçôes (e ainda de um modo muito simplificado, de forma discreta e, atualmente, ainda de modo apenas binário) e porque não tem um complexo sistema nervoso para uma aprendizagem, que efetivamente transforme seus processos em mudanças e, portanto, conquiste a aprendizagem e conhecimento.

Como ainda não fazemos nas escolas e universidades, e para que seja efetivada a aprendizagem do poder cognitivo disciplinador, teríamos que reprimir o sentir e o disciplinarizar dos processos de aprendizagem, como ritos religiosos dogmatizados que se tornam habituais ou, ainda, como afirma o sociólogo Bourdieu (1989 p 60-61): vestimos habitus rigorosos.

A idéia de habitus, na sociologia, é forte; vem da religião, de vestimentas de tradiçóes. A força tradicional do habitus provém de seu vínculo com as disposições estruturais pré-interativas, como os componentes de pertencimento a uma estrutura (classe, posição na estrutura e poder, lutas entre afirmação societal de gêneros...), mas a própria reprodução do habitus é dinâmica e quase nunca é igual a ela mesma das condiçôes pré-interativas. As condiçōes pré-interativas e pós-interativas compõem o habitus, que é um sistema de disposições duráveis, estruturas estruturadas predispostas ou estruturas estruturantes de práticas e de representaçóes, que podem ser objetivamente reguladas e regulares, sem que, por isso, sejam o produto da obediência a regras, objetivamente adaptadas a seu objetivo, sem supor a visada consciente dos fins e o domínio expresso das operações necessárias para atingi-los. Os 
Redescoberta da mente na educação: a expansão do aprender...

habitus, integrando todas as experiências passadas, são transferíveis e operam a cada momento como uma matriz de percepçóes, apreciações e ações, e tornam possível a realização de tarefas infinitamente diferenciadas, graças às transferências analógicas de esquemas que permitem resolver os problemas da mesma forma e graças às correçōes incessantes dos resultados obtidos, dialeticamente produzidas por estes resultados.

Não somos educados para a alegria do viver e, sim, para vestirmos hábitos, quase religiosos, operados por rituais repetitivos que os tornam cada vez mais naturais e reais. Numa pedagogia que estamos denominando como a pedagogia do acontecimento, diferente da pedagogia meramente cognitivista, o próprio aprender se volta, agora, para a experimentação da própria expansão bionatural do próprio ato de aprender, do próprio conhecer e da própria expansão do conhecimento.

Pensamos que um diálogo de modo muito ampliado com as ciências da mente pode nos ajudar a compreender melhor o labirinto cognitivista, cada vez mais computacional, em que nos encontramos na educação e, ao mesmo tempo, permitir renascer uma educação através da redescoberta da mente nos processos do aprendizado complexo, frente à conquista, também, do conhecimento complexo e, mais especificamente, do conhecimento do conhecimento.

\section{Recebido em junho de 2007 e aprovado em abril de 2008.}

\section{Notas}

1. Entendemos por estados simbióticos de mentitude, envolvidos em dinâmicas de aprendizagens, o percurso de estados da mente e do corpo, frente às diferentes singularidades de dobras micro e macro da realidade. É um percurso vital que envolve complexos processos de associações e conexôes de conflitos e cooperações, desde as entranhas comportamentais micromoleculares, até as micro e macrocomportamentais de nossos sentidos cotidianos, visíveis na escala macrofísica da realidade. Essa trajetória de estado de mentitude, em cada uma dessas dobras micro e macro da realidade, é singular e específica a cada uma dessas dobras da realidade, mas, ao mesmo tempo que são diferentes e singulares, inclusive em suas regras de comportamentos, essas dobras da realidade são também simultâneas. Por isso, o estado de mentitude é simbiótico (de symbion, que vive junto). A complexidade do estudo da aprendizagem reside na simbiose e na simbiogênese dos planos micro e macro da realidade, respeitando sempre as singularidades de cada plano, mas religando-os, pois esses planos singulares são, ao mesmo tempo, singulares e simultâneos, ou seja, operam em simultaneidade. Enfim, o processo de aprendizagem é uma conjunção de simbiose de eventos moleculares, neuroquímicos, cognitivos, emocionais e cinéticos que envolve uma complexa auto-eco-organização. 
2. Prometeu era um semideus que gostava muito dos homens. Conta a lenda que Prometeu subiu ao Olimpo, roubou o fogo dos deuses e o presenteou aos homens. O fogo trouxe aos homens a força do extraordinário pela sua luz, a força da imaginação, e estes puderam criar a civilização e fundar o inesperado da terra: a cidade do homem. Os deuses, ao descobrirem, instituíram um sofrido castigo a Prometeu. Era um castigo cruel que expressava a vingança de Zeus, o deus dos deuses, sobre o fato de ele ter permitido aos homens mortais o acesso em seu mundo ordinário do extraordinário. Zeus ordenou que o deusferreiro, Hefaístos, forjasse uma corrente indestrutível de elos invioláveis - incumbência que ele aceitou de bom grado, porque, afinal, fora de sua forja que Prometeu roubara o fogo. Com essa corrente indestrutível, Prometeu foi preso e amarrado no alto de um pico, no Cáucaso - onde hoje fica a Geórgia, na União Soviética, portanto, bem longe do Olimpo grego -, e condenado a ter o fígado eternamente devorado e dilacerado por uma águia. Cada vez que a águia terminasse de devorar parte do fígado de Prometeu, as dilaceraçôes da víscera renasceriam e a águia começaria de novo a devorá-la.

3. Alguns educadores também discutem sobre a significação das emoçôes na aprendizagem. Ver Restrepo (1998). Também foi muito importante como um marco histórico para este debate entre os educadores o livro de Humberto Maturana, Emoçōes e linguagem na educação e na política (1999). Ver, também, De Masi (1997).

4. Os principais componentes químicos (personagens hormonais) envolvidos pelos neurotransmissores nas trocas de informações cerebrais de nossa mente são: 1. Estrogênio - um hormônio poderoso que envolve o consumo de muita energia. $\mathrm{O}$ estrogênio é muito significativo e muito presente nas mulheres e também presente nos homens. O estrogênio estimula as ações de controle e precisão, mas de um modo "mais feminino", ou seja, gera reaçōes por vezes mais agressivas e por vezes mais sedutoras. É um hormônio que atua em parceria constante com a dopamina, a serotonina, a oxitocina, a acetilcolina e a norepinefrina (as substâncias cerebrais do bem-estar). 2. Progesterona - irmão poderoso do estrogênio; aparece intermitentemente e ora atua como uma nuvem de chuva que afeta os efeitos do estrogênio, ora como um agente suavizante; atua muito integrado com a alopregnanolona (é uma espécie de Valium do cérebro, ou a pílula da calma); 3. Testosterona - um hormônio masculino. É rápido, assertivo, focado, energético. É também poderoso e sedutor tal como o estrogênio, mas de um modo mais agressivo, frio, que não tem tempo para carinhos. Ver Brizendine (2006, p. XV e XVI).

5. O pioneiro deste tipo de análise - conhecido pelo nome de estudo de microrhythms culturais - é William Condon (1982).

6. O mesmo acontece com a latência, ou seja, o espaço de tempo entre o momento em que um falante pára de falar e o outro começa. Duas pessoas podem entrar numa conversa com padrōes muito diferentes, mas quase instantaneamente elas entram em acordo. Fazemos isso o tempo todo. Bebês de um ou dois dias sincronizam seus movimentos de cabeça, cotovelos, ombros, quadris e pés com os padrōes da fala dos adultos. A sincronia tem sido encontrada na interação de humanos e macacos. Faz parte da nossa programação genética e filogenética. Desde pequenos, aprendemos a ler as faces dos adultos e a observar seus fluxos em microrritmos.

7. Na complexidade, precisamos do processo de individuações, em favor de ações coletivas e não da simples individualização. Os processos de associações de células cerebrais individuais são envoltos em redes neuronais complexas da mente e são bem diferentes das estruturas modernas das macroindividualizações funcionais mecanicistas, onde, para agirmos coletivamente, precisaríamos nos anular como agentes individuais e suprimir nosso agenciamento individual a favor de estruturas, normalizações e instituições que permitiriam,

Educ. Soc., Campinas, vol. 30, n. 106, p. 151-174, jan./abr. 2009

Disponível em <http://www.cedes.unicamp.br> 
Redescoberta da mente na educação: a expansão do aprender...

assim, pela anulação do indivíduo, a plena realização do agenciamento das ações coletivas. $\mathrm{Na}$ complexidade organizacional, assim como nos processos celulares celebrais, quanto mais individuamos - isto é, individuar e não individualizar - para nos diferenciarmos, mais agimos coletivamente e vice-versa. Somos como são os solistas de Jazz: quanto mais dominamos nosso instrumento, mais solamos e, quanto mais solamos de modo complexo, mais qualificamos a orquestração coletiva.

8. Conforme afirmamos anteriormente neste artigo, durante décadas, fisiologistas se concentravam nos neurônios como os principais comunicadores do cérebro. Achava-se que as células gliais, apesar de superarem os neurônios na proporção de nove para um, tinham somente papel de manutenção: levar nutrientes dos vasos sanguíneos para os neurônios, manter um equilíbrio saudável de íons no cérebro e afugentar patógenos que tivessem escapado do sistema imunológico. Nos últimos anos, técnicas mais sensíveis de imagem mostraram que neurônios e células gliais dialogam entre si, do desenvolvimento embrionário até a velhice. As células gliais influenciam a formação de sinapses e ajudam a determinar as conexões neurais que se fortalecerão com o tempo. Essas alterações são essenciais para o aprendizado e o armazenamento de memórias duradouras. Trabalhos mais recentes mostram que as células gliais também se comunicam entre si numa rede independente, mas paralela à neural, influenciando o desempenho do cérebro. Os neurologistas ainda estão cautelosos e evitam atribuir importância à glia. Apesar disso, estamos entusiasmados com a perspectiva de que mais da metade do cérebro permanece inexplorada e pode representar uma mina de ouro em informaçôes sobre o funcionamento da mente.

\section{Referências}

ANDLER, D. Introduction aux sciences cognitives. Paris: Gallimard, 1992.

BOURDIEU, P. O poder simbólico. Rio de Janeiro: Bertrand Brasil, 1989.

BRIZENDINE, L. Como as mulheres pensam. Rio de Janeiro: Campus, 2006.

CONDON, S.W. Cultural microrhythms. In: Davis M. (Org.). Interaction rhyms: periodicity in communicative behavior. Nova York: Human Sciences, 1982. p. 53-76.

DAMÁSIO, R.A. O erro de Descartes: emoção, razão e o cérebro humano. São Paulo: Cia das Letras, 1996.

DELEUZE, G. A dobra: Leibniz e o barroco. Campinas: Papirus, 1991.

DE MASI, D. A emoção e a regra: os grupos criativos na Europa de 1850 a 1950. Rio de Janeiro: José Olympio, 1997. 
DE MASI, D.; FREI BETTO. Diálogos criativos. São Paulo: DeLeitura, 2002.

DIAMOND, M. Hormonal effects on the development of cerebral lateralization. Psychoneuroendocrinology, Berkeley, v. 16, p. 121-129, 1991.

FILDS, D.R. A outra metade do cérebro. Scientific American, São Paulo, v. 2, n. 24, p. 47-53, maio 2004.

FOLCAULT, M. Microfísica do poder. Rio de Janeiro: Grall, 1979.

FOLCAULT, M. Vigiar e punir: história da violência nas prisões. Petrópolis: Vozes, 1987.

GANASCIA, J.-G. Les sciences cognitives. Paris: Flammarion, 1996.

GLADWELL, M. O ponto do desequilíbrio. Rio de Janeiro: Rocco, 2002.

IZQUIERDO, I. A arte de esquecer: cérebro, memória e esquecimento. Rio de Janeiro: Vieira \& Lent, 2004.

IZQUIERDO, I. et al. Different molecular cascades in different sites of the brain control memory consolidation. Trends Neurosci, London, v. 9, n. 29, p. 496-505, set. 2006.

LENT, R. Cem bilhões de neurônios: conceitos fundamentais de neurociência. Rio de Janeiro: Atheneu, 2004.

LIMA, G. Nômades de pedra: teoria da sociedade simbiogênica contada em prosas. Porto Alegre: Escritos, 2005.

MATURANA, H. Emoções e linguagem na educação e na política. Belo Horizonte: UFMG, 1999.

MORIN, E. O método III: o conhecimento do conhecimento. Lisboa: Europa América, 1987.

PESSOA, F. Livro do desassossego. São Paulo: Cia das Letras, 2001.

POMBO, O. Interdisciplinaridade: ambições e limites. Lisboa: Relógio d'Água, 2004. p. 73-104. 
Redescoberta da mente na educação: a expansão do aprender...

POMBO, O. Práticas interdisciplinares. Sociologias, Porto Alegre, v. 8, n. 15, p. 208-249, 2006.

RESTREPO, L.C. O direito à ternura. Petrópolis: Vozes: 1998.

SCHULTZ, B. Sanatório. Rio de Janeiro: Imago, 1994.

ZIMMER, C. A fantástica história do cérebro. Rio de Janeiro: Elsevier, 2004 . 